\title{
Percepción ética del oficio periodístico. Realidad universitaria vs. realidad laboral
}

\author{
Recibido: 02 de diciembre de 2016 \\ Aceptado: 01 de junio de 2017 \\ Publicado: 27 de noviembre de 2017
}

\author{
constanza.hormazabal@uniacc.cl \\ Constanza Hormazábal \\ Universidad de Artes, Ciencias y Comunicación (Chile)
}

\begin{abstract}
Resumen: El informe "Estudiantes de Periodismo en Chile: Percepción sobre la profesión, su futuro laboral y el desempeño de los medios" (Mellado y otros, 2015), que recoge la visión de estos acerca del campo laboral, evaluación y uso de los medios, amenazas y futuro del periodismo, y ética, entre otros, es el punto de partida de una investigación exploratoria para dar cuenta de la percepción ética de los estudiantes de periodismo, frente a prácticas controversiales y su relación con su inserción laboral. A partir del análisis y profundización de los hallazgos de este informe y la contrastación con las mallas curriculares de las escuelas de periodismo participantes, se extrapola la visión de los estudiantes con la realidad observada en su primera experiencia profesional, a partir de la percepción de los editores de medios de comunicación. De esta forma, se busca determinar de qué manera la percepción ética del estudiante se pone a prueba en su primera experiencia profesional.
\end{abstract}

Palabras clave: Ética periodística, formación académica del periodista, medios de comunicación, estudiantes de periodismo, escuelas de periodismo, educación superior, prácticas controversiales.

\begin{abstract}
The report “Journalism' students in Chile: Perception of the profession, their future work field and the performance of the media" (Mellado \& cols., 2015), which includes their perspective about career field, evaluation and use of the media, threats and future of journalism, and ethics, among others, is the starting point of an exploratory investigation to account the ethical perception of journalism students, against controversial practices and their relation to join the labor market. Based on the analysis, getting deeper in the findings of this report and the contrast with the curricula of the participating journalism schools, the students'vision is extrapolated from
\end{abstract}


the reality observed in their first professional experience, based on the perception of the media editors. In this way, this report tries to determine how the student's ethical perception is put to the test in his first professional experience.

Key words: Journalistic Ethics, Academic Journalist Formation, Media, Journalism Students, Journalism Schools, Higher Education, Controversial Practices.

\section{Introducción}

En el ejercicio periodístico, el rol de la ética profesional ha sido indisoluble. Comprender esta premisa implica exponer y analizar, no solo los aspectos deontológicos que dan las bases a la formación de periodistas, sino que también la manera en que se aborda en la formación universitaria y cómo esto se plasma en el ejercicio de la profesión.

A partir de lo anterior, según Shoemaker y Reese, los valores profesionales y las actitudes del periodismo pueden ser aprendidos e internalizados a través de la experiencia e interacción con diversos ambientes y diferentes fuentes, incluso aquellas que provienen del ámbito educativo (ápud Mellado y otros, 2015: 4).

La revisión y reflexión de la ética periodística, si bien es (o más bien debiese ser) constante, en ocasiones suele salir a la palestra cuando ocurre algún conflicto a partir de, por ejemplo, cómo se cubre una noticia de un hecho trágico, se expone la dignidad de una persona o se da a conocer una información sin el respectivo chequeo de fuentes.

Al momento que ocurren estas contingencias, es frecuente que en el debate que se gesta en la opinión pública se haga mención a los valores de la profesión y en ocasiones se enjuicia la falta de ética en el ejercicio periodístico, de manera genérica, por lo que ese episodio termina transformándose en ocasiones en la noticia y no aquello que se buscaba dar a conocer o la manera en que se debió dar a conocer.

En ese sentido, la necesidad de la ética profesional en la formación de periodista data de sus orígenes y ello se refuerza en una célebre cita de Pulitzer (1904: 667): "Naturalmente, habrá un curso de ética, pero la formación de principios éticos no debe limitarse a eso... debe impregnar todos los cursos". Por tal razón, resulta de suma relevancia investigar la formación periodística, en específico el ámbito de la ética profesional, para luego comprender la manera en que enfrentan el ejercicio de la profesión.

\section{La percepción de estudiantes de periodismo: amenazas y ética}

En el caso chileno, los estudios sistemáticos sobre estudiantes de periodismo han sido escasos (Mellado y otros, 2015: 4), en cuanto a conocer la visión y motivaciones de quienes escogen la profesión, sus áreas de interés, amenazas hacia la profesión, entre otros. Sin embargo, en el 2015 se dio a conocer el informe "Estudiantes de Periodismo en Chile: 
Percepción sobre la profesión, su futuro laboral y el desempeñó de los medios", liderado por la Universidad Católica de Valparaíso, en colaboración con otras 13 casas de estudios (entre ellas UNIACC) y para ello se seleccionó instituciones de diferentes características para abarcar la heterogeneidad de la enseñanza de la carrera en Chile ${ }^{1}$.

Este estudio recoge y analiza la percepción y visión de estudiantes de periodismo sobre la carrera, la educación del periodismo, su futuro laboral y la profesión. La realización de este se encuentra en el marco del proyecto internacional "Journalism Students Across the Globe: Professionalization, Identity and Challenges in a Changing Environment" (2014), llevado a cabo en más de 30 países, para analizar la forma en que la educación del periodismo influencia las percepciones de los estudiantes y sus actitudes hacia la carrera (Mellado y otros, 2015: 4 y 5).

A partir de este informe, luego de aplicar una encuesta a 1985 estudiantes, fue posible tener respuesta a interrogantes, tales como: ¿cuáles son las principales motivaciones de los estudiantes para escoger periodismo?, ¿cuáles son los principales roles profesionales del periodismo?, ¿en cuáles áreas del periodismo les gustaría trabajar?, ¿cómo evalúan el desempeño de los medios del país? y ¿cuáles creen que son las mayores amenazas para el ejercicio de la profesión? (Mellado y otros, 2015: 5).

Las dimensiones consideradas en este estudio son: perfil del estudiante de periodismo en Chile, campo laboral, evaluación y uso de los medios, amenazas y futuro del periodismo, formación universitaria, motivaciones y roles profesionales y prácticas profesionales y ética (Mellado y otros, 2015: 7). Este último punto es el que se analiza y la razón para ello surge en la dimensión que se refiere a las amenazas y futuro del periodismo.

En la siguiente tabla (figura 1) se indica en qué medida los estudiantes creen que los siguientes aspectos representan una mayor amenaza para el ejercicio de la profesión. Cabe precisar que las opciones consideraban las categorías de ninguna amenaza, poca amenaza, alguna amenaza, gran amenaza y extrema amenaza (Mellado y otros, 2015: 32).

Figura 1: Aspectos que representen una amenaza para el ejercicio de la profesión.

\begin{tabular}{|l|c|c|}
\hline & GRAN AMENAZA & AMENAZA EXTREMA \\
\hline Interferencia del Estado en los medios & $29.5 \%$ & $24.3 \%$ \\
\hline Concentración de la propiedad & $28.9 \%$ & $37.4 \%$ \\
\hline Regulaciones y marcos legales & $25.7 \%$ & $9.6 \%$ \\
\hline Creciente dependencia en periodistas freelance & $16.7 \%$ & $7.4 \%$ \\
\hline Demanda de ganancias por parte de los inversionistas & $33.2 \%$ & $22.0 \%$ \\
\hline Acceso a la información & $21.1 \%$ & $9.8 \%$ \\
\hline Creciente velocidad de ritmos de trabajo & $18.6 \%$ & $6.6 \%$ \\
\hline Propiedad extranjera en los medios & $26.3 \%$ & $18.1 \%$ \\
\hline Amenazas físicas contra los periodistas & $21.1 \%$ & $23.7 \%$ \\
\hline
\end{tabular}

1. En Chile, la carrera de periodismo se imparte en 27 universidades. 


\begin{tabular}{|l|c|c|}
\hline Recursos financieros limitados & $34.4 \%$ & $21.0 \%$ \\
\hline Periodismo orientado al mercado & $28.3 \%$ & $40.8 \%$ \\
\hline Censura & $21.2 \%$ & $42.3 \%$ \\
\hline Relaciones públicas y lobistas & $25.7 \%$ & $18.5 \%$ \\
\hline Preparación profesional inadecuada & $26.5 \%$ & $29.9 \%$ \\
\hline $\begin{array}{l}\text { Competencia por parte de los medios digitales, tales } \\
\text { como el periodismo ciudadano }\end{array}$ & $16.5 \%$ & $8.7 \%$ \\
\hline Influencia de los anunciantes en el contenido & $27.7 \%$ & $21.6 \%$ \\
\hline Complicidad entre los medios y los políticos & $32.4 \%$ & $42.6 \%$ \\
\hline Auto-censura & $29.1 \%$ & $29.0 \%$ \\
\hline La calidad de la enseñanza del periodismo & $28.6 \%$ & $19.4 \%$ \\
\hline Periodismo partidista & $32.4 \%$ & $26.7 \%$ \\
\hline Debilidad en la ética profesional & $28.3 \%$ & $42.1 \%$ \\
\hline
\end{tabular}

Fuente: Mellado y otros (2015: 32).

Las 5 principales amenazas que identifican los estudiantes son, en primer lugar, complicidad entre los medios y los políticos (75\%); luego, la debilidad en la ética profesional (70.4\%); tercero, el periodismo de mercado (69.1\%); cuarto, la concentración de la propiedad $(66.3 \%)$; y en quinto lugar, la censura (63.5\%). Si analizamos este resultado desde la academia, podríamos concluir lo siguiente: de las cinco amenazas, cuatro corresponden a factores externos y sólo uno es claramente interno y de injerencia y competencia de los programas académicos que imparten la carrera de periodismo.

Si los estudiantes consideraban una de las mayores amenazas la debilidad en la ética profesional, la siguiente tabla (figura 2) expone los resultados en la dimensión "Prácticas profesionales y éticas" de este estudio. En ella, se les pide a los estudiantes que indiquen en qué medida justificarían ciertas prácticas periodísticas en la cobertura noticiosa. Se enumeraron 11 prácticas controversiales y se les preguntó cuáles de ellas serían justificadas y cuáles no aprobarían bajo ninguna circunstancia (Mellado y otros, 2015: 42).

Figura 2: Justificación de prácticas controversiales.

\begin{tabular}{|l|c|c|c|}
\hline & LO JUSTIFICARÍA & $\begin{array}{c}\text { LO } \\
\text { SIEMPRE } \\
\text { JUSTFICARÍA } \\
\text { EN CIERTAS } \\
\text { OCASIONES }\end{array}$ & $\begin{array}{c}\text { NO LO } \\
\text { JUSTIFICARÍA } \\
\text { BAJO } \\
\text { NINGUNA }\end{array}$ \\
\hline Pagar por información confidencial & $6.2 \%$ & $53.6 \%$ & $40.3 \%$ \\
\hline $\begin{array}{l}\text { Utilizar documentos confidenciales de gobierno sin } \\
\text { autorización }\end{array}$ & $12.9 \%$ & $57.5 \%$ & $29.6 \%$ \\
\hline Fingir ser otra persona & $8.2 \%$ & $48.6 \%$ & $43.3 \%$ \\
\hline No proteger la confidencialidad de una fuente & $8.4 \%$ & $15.9 \%$ & $75.7 \%$ \\
\hline $\begin{array}{l}\text { Presionar a informantes si no están dispuestos a entregar } \\
\text { información }\end{array}$ & $14.4 \%$ & $50.7 \%$ & $34.8 \%$ \\
\hline $\begin{array}{l}\text { Hacer uso de cartas, fotografias o documentos personales } \\
\text { sin autorización. }\end{array}$ & $6.1 \%$ & $41.4 \%$ & $52.5 \%$ \\
\hline Utilizar cámaras o micrófonos ocultos & $11.0 \%$ & $73.1 \%$ & $15.9 \%$ \\
\hline
\end{tabular}




\begin{tabular}{|l|c|c|c|}
\hline $\begin{array}{l}\text { Conseguir trabajo en una empresa u organización para } \\
\text { obtener información desde adentro }\end{array}$ & $19.3 \%$ & $59.3 \%$ & $21.4 \%$ \\
\hline Recrear o dramatizar noticias por parte de actores & $18.4 \%$ & $48.1 \%$ & $33.5 \%$ \\
\hline Publicar historias sin verificar el contenido & $5.8 \%$ & $10.7 \%$ & $83.4 \%$ \\
\hline Aceptar dinero de fuentes informativas & $6.4 \%$ & $11.1 \%$ & $82.5 \%$ \\
\hline
\end{tabular}

Fuente: Mellado y otros (2015: 42).

En función de estos resultados, se puede constatar que las prácticas más reprochables serían, en primer lugar, publicar historias sin verificar el contenido; luego, aceptar dinero de fuentes informativas; y en tercer lugar, el no proteger la confidencialidad de la fuente. En esta dimensión, además, se precisaron otros hallazgos, como por ejemplo el tener o no experiencia laboral no genera diferencias significativas en la aprobación o rechazo de estas prácticas por parte de los estudiantes. En términos de género, son los hombres los que tienden a aprobar estas prácticas en mayor medida que las mujeres, aunque las diferencias no son tan pronunciadas (Mellado y otros, 2015: 43).

El año cursado en la carrera es otro factor que genera ciertas diferencias. A medida que los estudiantes avanzan en su formación universitaria, rechazan en mayor medida pagar por información confidencial y no proteger la confidencialidad de una fuente, mientras que aprueban mayormente usar documentos confidenciales del gobierno sin autorización y fingir ser otra persona (Mellado y otros, 2015: 43).

\section{Identificación de las asignaturas de ética periodística}

A partir de los resultados de lo que podríamos considerar la primera radiografía a la percepción de los estudiantes de periodismo, se realizó un estudio exploratorio que busca profundizar en los aspectos vinculados a las amenazas y en mayor medida a la ética profesional, teniendo como indicador el año cursado de la carrera. Para ello, se realizó un catastro de las mallas curriculares o plan de estudio de las Escuelas de Periodismo consideradas en el informe, a objeto de identificar las asignaturas vinculadas a la ética periodística (figura 3).

Un primer aspecto que resulta de interés verificar es si las cátedras asociadas a la ética periodística tendrían alguna influencia en los resultados, es decir, si la incidencia de estas asignaturas modifica la percepción ética de los estudiantes, conforme avancen en la carrera. Para ello, se identificó aquellas cátedras bajo las etiquetas de "ética", "ética profesional", "deontología periodística", "ética periodística", "ética y legislación periodística”, entre otras.

Figura 3: Asignaturas de ética periodística según universidad.

\begin{tabular}{|c|c|c|c|c|c|c|c|c|c|c|c|c|c|c|}
\hline $1^{\circ}$ año & & & $\mathrm{X}$ & & & & & & & & & & & \\
\hline $2^{\circ}$ año & & & & $\mathrm{X}$ & & $\mathrm{X}$ & $\mathrm{X}$ & & & & & $\mathrm{X}$ & $\mathrm{X}$ & \\
\hline $3^{\circ}$ año & & $\mathrm{X}$ & & & $\mathrm{X}$ & & $\mathrm{X}$ & $\mathrm{X}$ & $\mathrm{X}$ & & $\mathrm{X}$ & & & $\mathrm{X}$ \\
\hline $4^{\circ}$ año & $\mathrm{X}$ & & & & & & & & & $\mathrm{X}$ & & & & \\
\hline
\end{tabular}




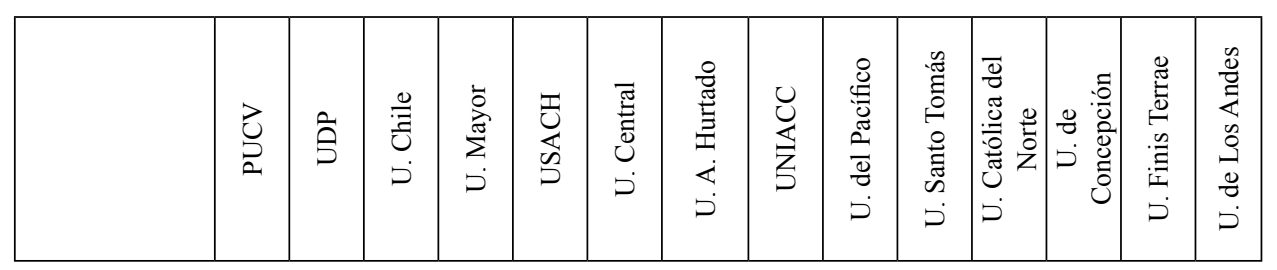

Fuente: Elaboración propia.

Todos los programas académicos tienen, en su mayoría, una asignatura vinculada a la materia. El año de estudio cursado donde hay más concentración de cursos es el quinto o sexto semestre, correspondiente al tercer año de la carrera, es decir, a la mitad de su ciclo de estudios. En aquellos casos que se visualiza más de una asignatura, la primera corresponde a ética general y luego a una específica en la disciplina. El nombre mayormente utilizado corresponde a "ética periodística" o "ética y legislación periodística"

Respecto a los estudios o a las publicaciones relacionadas con la enseñanza de la ética periodística en las universidades chilenas, no es posible encontrar mayores antecedentes. Sin embargo, en relación con el rol del docente, en el 2005 se organizó un primer encuentro de profesores de estas asignaturas, a cargo del Tribunal de Ética y Disciplina del Colegio de Periodistas. En esa oportunidad, se analizaron los programas de los cursos de quienes representaron a distintas universidades y se comprobó que en muchas de ellas resultaba difícil encontrar profesores. Las vacantes se solían completar en su mayoría por abogados, quienes generalmente se enfocaban en la ley, más que en consideraciones éticas como tal.

Santibáñez (2013: 36 y 37) recuerda que "en la reunión hubo consenso que la mejor metodología para la enseñanza es el análisis de casos. Se hizo evidente, además, que en el caso de los profesores periodistas, aunque tengan experiencia en la labor profesional, no siempre manejan correctamente algunos conceptos básicos ni cuentan con suficiente apoyo para sus cursos"

A partir de los datos obtenidos de las asignaturas vinculadas a la ética periodística y su ubicación en los planes de estudios, se identificó la variación en la percepción de las prácticas controversiales, conforme el año de la carrera cursada (figura 4), teniendo como referencia la ubicación de las asignaturas en el punto anterior, para determinar si hay variaciones importantes, como por ejemplo, si las prácticas más condenables aumentan su rechazo, a mayor nivel cursado.

2. Si bien esta investigación no considera ahondar en los programas de las asignaturas (vinculadas a la ética periodística) y en el perfil del docente que debería impartir esa cátedra, resulta relevante manejar esos antecedentes para futuras investigaciones que permitan indagar en los resultados que más adelante expone este estudio. 
Figura 4: Prácticas controversiales. Variación según año cursado.

\begin{tabular}{|c|c|c|c|c|c|c|}
\hline PREGUNTAS & & $1^{\circ} \mathrm{AÑ} O$ & $2^{\circ} \mathrm{AÑO}$ & $3^{\circ} \mathrm{AÑO}$ & $4^{\circ} \mathrm{A} \tilde{\mathbf{N O}}$ & $5^{\circ} \mathrm{A} \tilde{\mathbf{N O}}$ \\
\hline \multirow{3}{*}{$\begin{array}{c}\text { Pagar por información } \\
\text { confidencial }\end{array}$} & Siempre & $8.7 \%$ & $6.7 \%$ & $4.1 \%$ & $2.1 \%$ & $6.2 \%$ \\
\hline & En ciertas ocasiones & $57.1 \%$ & $54 \%$ & $48.5 \%$ & $52.4 \%$ & $47.3 \%$ \\
\hline & $\begin{array}{l}\text { Bajo ninguna } \\
\text { circunstancia }\end{array}$ & $32.5 \%$ & $38.6 \%$ & $47.1 \%$ & $44 \%$ & $44.1 \%$ \\
\hline \multirow{3}{*}{$\begin{array}{l}\text { Utilizar documentos } \\
\text { confidenciales de } \\
\text { gobierno sin autorización }\end{array}$} & Siempre & $12.4 \%$ & $12.5 \%$ & $13.5 \%$ & $12.9 \%$ & $13.7 \%$ \\
\hline & En ciertas ocasiones & $50.8 \%$ & $54.5 \%$ & $63.8 \%$ & $62.6 \%$ & $61 \%$ \\
\hline & $\begin{array}{l}\text { Bajo ninguna } \\
\text { circunstancia }\end{array}$ & $35.4 \%$ & $32 \%$ & $22.6 \%$ & $24 \%$ & $25.3 \%$ \\
\hline \multirow{3}{*}{$\begin{array}{c}\text { No proteger la } \\
\text { confidencialidad de una } \\
\text { fuente }\end{array}$} & Siempre & $10.4 \%$ & $8.2 \%$ & $5.9 \%$ & $5.1 \%$ & $10.4 \%$ \\
\hline & En ciertas ocasiones & $17.7 \%$ & $14.2 \%$ & $15 \%$ & $16.2 \%$ & $12 \%$ \\
\hline & $\begin{array}{l}\text { Bajo ninguna } \\
\text { circunstancia }\end{array}$ & $69.5 \%$ & $75.7 \%$ & $77.4 \%$ & $76.3 \%$ & $77.2 \%$ \\
\hline \multirow{3}{*}{$\begin{array}{l}\text { Presionar a informantes } \\
\text { si no están dispuestos a } \\
\text { entregar información }\end{array}$} & Siempre & $13.4 \%$ & $13.5 \%$ & $15.6 \%$ & $16.5 \%$ & $12.9 \%$ \\
\hline & En ciertas ocasiones & $52.1 \%$ & $48.7 \%$ & $47.6 \%$ & $52.7 \%$ & $46.9 \%$ \\
\hline & $\begin{array}{l}\text { Bajo ninguna } \\
\text { circunstancia }\end{array}$ & $32.5 \%$ & $37.1 \%$ & $35 \%$ & $29.9 \%$ & $40.2 \%$ \\
\hline \multirow{3}{*}{ Fingir ser otra persona } & Siempre & $7.3 \%$ & $9.9 \%$ & $10.6 \%$ & $6.9 \%$ & $5.4 \%$ \\
\hline & En ciertas ocasiones & $42.4 \%$ & $42.2 \%$ & $51.8 \%$ & $55.1 \%$ & $60.2 \%$ \\
\hline & $\begin{array}{l}\text { Bajo ninguna } \\
\text { circunstancia }\end{array}$ & $49.2 \%$ & $47 \%$ & $37.6 \%$ & $37.7 \%$ & $34.4 \%$ \\
\hline \multirow{3}{*}{$\begin{array}{l}\text { Utilizar cámaras o } \\
\text { micrófonos ocultos }\end{array}$} & Siempre & $13 \%$ & $11.8 \%$ & $10 \%$ & $8.7 \%$ & $8.3 \%$ \\
\hline & En ciertas ocasiones & $70.2 \%$ & $73 \%$ & $69.4 \%$ & $75.1 \%$ & $78.4 \%$ \\
\hline & $\begin{array}{l}\text { Bajo ninguna } \\
\text { circunstancia }\end{array}$ & $15.7 \%$ & $14.5 \%$ & $19.4 \%$ & $15.9 \%$ & $12.9 \%$ \\
\hline \multirow{3}{*}{$\begin{array}{l}\text { Publicar historias sin } \\
\text { verificar el contenido }\end{array}$} & Siempre & $7.3 \%$ & $5.3 \%$ & $5.6 \%$ & $3.9 \%$ & $5.4 \%$ \\
\hline & En ciertas ocasiones & $12.4 \%$ & $10.1 \%$ & $8.8 \%$ & $8.1 \%$ & $12.9 \%$ \\
\hline & $\begin{array}{l}\text { Bajo ninguna } \\
\text { circunstancia }\end{array}$ & $79.1 \%$ & $84.3 \%$ & $85.3 \%$ & $87.4 \%$ & $79.7 \%$ \\
\hline \multirow{3}{*}{$\begin{array}{l}\text { Aceptar dinero de fuentes } \\
\text { informativas }\end{array}$} & Siempre & $8.4 \%$ & $6.5 \%$ & $4.7 \%$ & $3.9 \%$ & $6.6 \%$ \\
\hline & En ciertas ocasiones & $15 \%$ & $9.4 \%$ & $9.1 \%$ & $8.7 \%$ & $8.7 \%$ \\
\hline & $\begin{array}{l}\text { Bajo ninguna } \\
\text { circunstancia }\end{array}$ & $75.3 \%$ & $83.9 \%$ & $85.9 \%$ & $86.8 \%$ & $83.4 \%$ \\
\hline
\end{tabular}

Fuente: Elaboración propia.

En función de estos datos, se puede observar que el rechazo a "pagar por información confidencial" aumenta a partir del tercer año de la carrera, pero con un crecimiento máximo de 9 puntos, hasta llegar a un $47 \%$ de rechazo. La "utilización de documentos confidenciales del gobierno sin autorización" tiende a ser aceptada en ciertas ocasiones, también a partir del tercer año de la carrera y con una variación porcentual similar al punto anterior, logrando un nivel de aceptación condicional de $63.8 \%$. "No proteger la confidencialidad 
de una fuente", aumenta levemente su rechazo en segundo año y se mantiene sostenido hasta el quinto, donde alcanza un $77.2 \%$.

Este aspecto es de suma relevancia entenderlo en el contexto que establece el código de ética del Colegio de Periodistas de Chile (2015), en el cual indica que "el periodista debe transparentar sus fuentes para legitimar ante la sociedad la información entregada. Sólo debe silenciarlas si estas se lo pidieren, previa confirmación de su idoneidad y confiabilidad, respetando así la confianza otorgada al entregársele antecedentes reservados”.

En cuanto a "presionar a informantes", se registra un alza en el rechazo hacia quinto año de la carrera. Empero, es mayor su aceptación bajo ciertas circunstancias, donde incluso se observan hasta 10 puntos de diferencia. La práctica "fingir ser otra persona" aumenta bajo ciertas circunstancias: al igual que la "utilización de cámaras ocultas", se observa un alza en el criterio de utilización bajo ciertas circunstancias. No obstante, en el segundo caso, es importante tener en cuenta que, de acuerdo con las orientaciones programáticas de los canales de televisión en Chile, se establece y es de consenso que la investigación encubierta o utilizando cámaras o micrófonos ocultos, sólo es justificable por excepción y siempre deberá ser informada y aprobada previamente por la alta dirección del canal y bajo ciertos requisitos: $a$ ) que de otra forma sea imposible obtener la información y $b$ ) que se trate de informaciones de relevancia pública (Chilevisión, 2006). Por lo tanto, la tendencia a "bajo ciertas circunstancias" está en sintonía con los lineamientos editoriales de los medios de comunicación.

La "publicación de información sin verificar el contenido" aumenta su rechazo hacia el cuarto año de la carrera hasta alcanzar un $87.4 \%$. Sin embargo, en el quinto año cae a casi el mismo porcentaje de inicio de la carrera. "Aceptar dinero de fuentes informativas" también aumenta el rechazo hacia los últimos años de carrera y es la que mantiene el mayor porcentaje de no aceptación de manera más sostenida. Con respecto del primero punto (la verificación de contenidos) no deja de preocupar, pese a que el porcentaje de aceptación sea bajo, que igualmente exista un margen en el que se percibe como una práctica factible de realizar, toda vez que el código de ética del Colegio de Periodistas de Chile (2015) establece en su inicio que "el compromiso del periodista con la sociedad y su deber de entregar información verificable a la ciudadanía es irrenunciable”, siendo este aspecto ampliamente compartido en la formación de periodistas en el país.

En términos generales y a partir de los resultados, se puede observar que las variaciones más pronunciadas en algunas preguntas tienen a coincidir con las asignaturas específicas en el ámbito de la ética y legislación periodística. Por lo tanto, podríamos corroborar un grado de impacto, pero no en mayor grado. Es decir, no es determinante que las materias de esta índole generan un cambio sustancial e importante en la percepción de los estudiantes, ya que el aumento o disminución varía como máximo en poco más de diez puntos de diferencia.

En sintonía con lo anterior, la brecha más pronunciada en cuanto a rechazar una práctica en la categoría "bajo ninguna circunstancia", la obtiene el "pago por información confidencial" la que inicia en primer año en $32.5 \%$ y aumenta al quinto año a $44.1 \%$. En este sentido, y a partir de los resultados expuestos, cabe enfatizar que el cambio en la percepción del alumno no varía mayormente desde que ingresan a la carrera hasta que están prontos a egresar. 


\section{Percepción de editores frente a estudiantes en práctica}

A partir de los resultados de la primera parte de este estudio exploratorio, la segunda etapa consistió en contrastar la visión de los estudiantes (que se expuso anteriormente) con la realidad observada en su primera experiencia profesional por parte de los editores de medios de comunicación, quienes son sus tutores en su acercamiento al mundo laboral. Para ello, se consultó a más de 80 editores si habían constatado en el último año, la utilización de las mismas prácticas controversiales (consideradas en el estudio) por parte de los alumnos en práctica.

La muestra consideró, de manera equitativa, a periodistas que se desempeñan en medios impresos (diarios y revistas), televisión, radio e Internet, en las secciones de "Política", "Economía", "Judicial", "Tribunales", "Crónica", "Nacional" y "Deportes". Se consideraron estos frentes noticiosos como aquellos en los cuales se podrían evidenciar estas prácticas, en atención al tipo de hechos noticiosos que cubren o bien, porque han sido frentes en los cuales ha existido algún antecedente en la utilización de prácticas controversiales. Cabe precisar que los periodistas encuestados se corresponden con las mismas regiones de la muestra de estudiantes y se buscó un equilibrio en función de casas de estudios y medios de comunicación por regiones.

La muestra se realizó desde fines de febrero y durante marzo de 2016, considerando que en ese periodo existe el mayor número de alumnos en práctica que están prontos a finalizar esta etapa en un medio de comunicación. En términos generales, solo un 44\% indicó haber detectado prácticas controversiales por parte de estudiantes (figura 5). Cabe precisar que aquellos que respondieron "No", indicaron que no solo en el último año, sino que nunca habían constatado este tipo de práctica al interior del medio en que trabajan.

Figura 5: Identificación en el último año de una de las 11 prácticas controversiales.

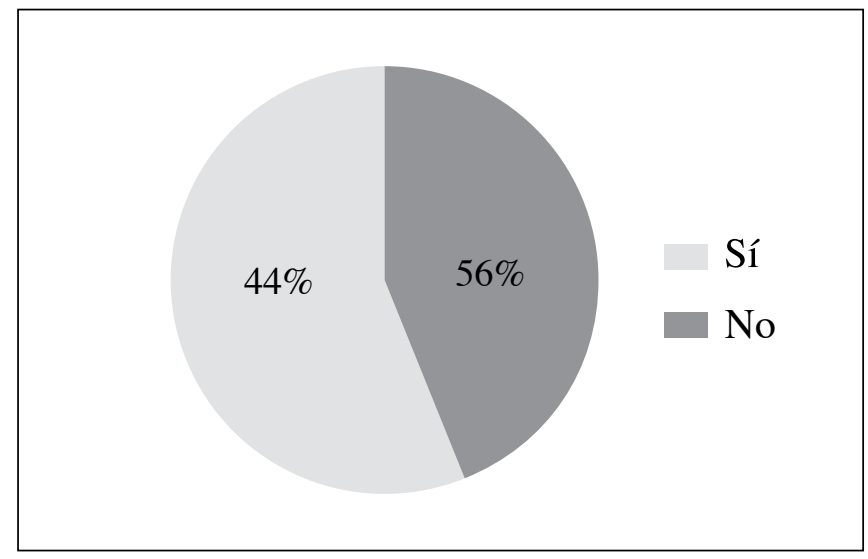

Fuente: Elaboración propia. 
En cuanto al tipo de medio (figura 6), se observan diferencias más marcadas. En impresos, solo un 33\% identificó prácticas; en televisión hay un aumento con un $60 \%$ (más adelante se desglosa en las razones); en Internet se distribuye en partes iguales. En el caso de la radio, el comportamiento es el mismo que en medios escritos.

Figura 6: Prácticas controversiales según tipo de medio.

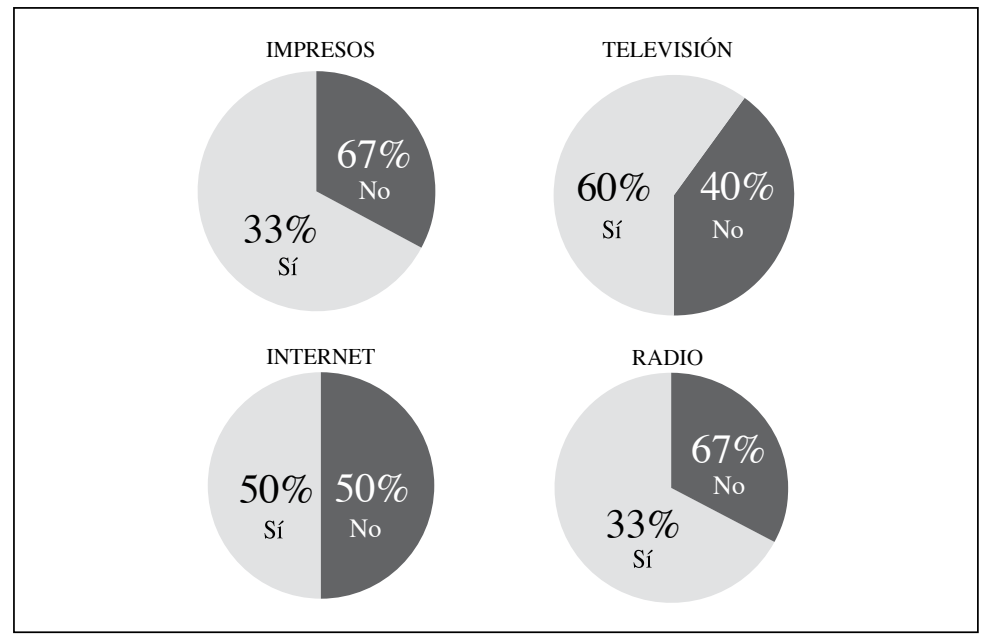

Fuente: Elaboración propia.

Respecto al detalle de las prácticas controversiales (figura 7), la más señalada es "publicar sin verificar el contenido". En este sentido, es importante precisar que los periodistas que identificaron esta práctica aclaran que el medio sí publicó luego de verificar el contenido, siendo el editor quien detectó la falta en los despachos realizados por los alumnos en práctica.

Figura 7: Prácticas controversiales detectadas por editores.

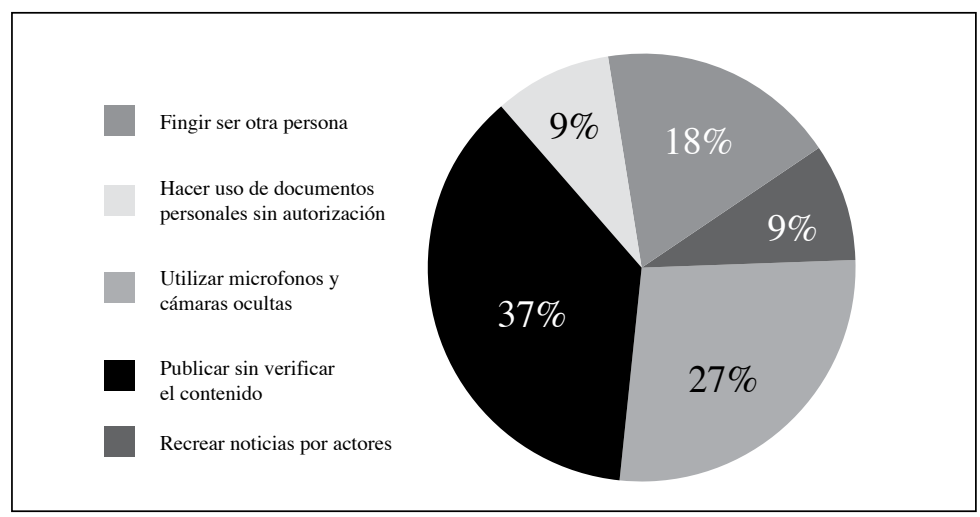

Fuente: Elaboración propia. 
La segunda más identificada es la utilización de micrófonos y cámaras ocultas, razón por la cual en el caso de la televisión (como indica la figura 6) se identifica un porcentaje mayor de prácticas controversiales, en comparación con otros tipos de medios. Con relación a las prácticas que tuvieron mayor mención, es importante destacar el común denominador recogido por parte de los editores, para comprender las razones de los errores o faltas en que incurren los practicantes.

En primer lugar, destacan que los estudiantes en práctica tienen a creer que las redes sociales son una fuente válida por el solo hecho que hay detrás una persona que denuncia. Desde este punto de vista, muchos estudiantes utilizan las redes sociales no solo como un medio de información, sino que también como una fuente de "reporteo". Al respecto, se advierte la necesidad (por parte de los practicantes) de evaluar el peso específico de la fuente, es decir, si a partir de esa sola fuente se sustenta la noticia por sí sola. A partir de lo anterior, se reitera la necesidad de chequear y re chequear los datos que se reportean, ante el uso masivo de información disponible en redes sociales.

En cuanto al uso de cámaras o micrófonos ocultos, la tendencia de los practicantes es realizar grabaciones en sectores donde está prohibido, mas que descubrir a personas o develar acciones o eventuales delitos. Asimismo, los editores advierten la necesidad de establecer límites de acuerdo con la ley vigente al minuto de grabar a personas sin su autorización, por ejemplo, enfermos en un hospital o menores de edad. Muchas veces los alumnos están en el límite de lo ético y los editores deben reforzar este punto en la práctica diaria.

Por lo anterior, es válido precisar nuevamente lo que indican las orientaciones programáticas de los canales de televisión. Un ejemplo de ello es Canal 7 Televisión Nacional de Chile, señal pública que precisa que deben evitarse en lo posible el registro audiovisual, de audio o imágenes que intervengan indebidamente la intimidad de una persona, ya que puede afectar sus derechos fundamentales y solo se remite a un uso excepcional para responder a razones muy justificadas, tales como: servir a un propósito noticioso importante que no es posible obtenerlo con métodos abiertos de captación, existencia de indicios que las imágenes develarán conductas criminales o antisociales, que no se revele la identidad de las personas que se haya captado. Además, precisa que no se utilizarán cámaras no visibles para grabar a niños o personas en situación de desventaja cuando estos sean perjudiciales $(T V N, 2017:$ 152).

En este sentido, la observación que indica el editor tiene estrecha relación con los aspectos que es necesario reforzar entre los estudiantes en práctica, al momento que llegan con el resultado de su reporteo o previo a este.

\section{Reflexiones a partir de los resultados}

Tras realizar este estudio, desde el quehacer académico surgen inquietudes y también una invitación a la reflexión, lo que se traduce en nuevos desafíos para la formación de los próximos periodistas. El primero de ellos tiene relación con el impacto que generan 
las asignaturas asociadas a la ética. No deja de llamar la atención que el alumno (desde que ingresa hasta que egresa de la carrera) no da cuenta de una variación importante en su percepción de las conductas éticas que resultan reprochables en el ejercicio periodístico, más aún cuando ellos mismos consideran esta variable como una amenaza hacia la profesión.

Determinar si la ubicación de la asignatura o la cantidad de estas puedan incidir en la percepción ética, deja una arista para nuevas investigaciones. Al respecto, podemos encontrar antecedentes en la formación de periodistas en Europa que dan cuenta de estudios al respecto, pero sin una mirada única o ampliamente consensuada de cómo abordarlo.

En este sentido, Díaz del Campo (2013) indaga en cuál debería ser el lugar de la ética en los planes de estudios y a partir de una extensa revisión bibliográfica, concluye que no hay una respuesta categórica y que lo relevante es su presencia en los currículos de estudios. Por una parte, plantea que la ventaja de incluirlos en los primeros años generaría mayor toma de conciencia de los alumnos y su importancia desde un inicio de su formación. Por el contrario, expone que quienes defienden la incorporación hacia finales de la carrera argumentan que los estudiantes tendrían mayor conocimiento sobre la naturaleza del ejercicio profesional por lo que les resultaría más simple comprender cuestiones éticas.

Más allá de la ubicación en el plan de estudios y la búsqueda de un consenso, resulta relevante comprender el ejercicio práctico de la profesión al interior del plan de estudios. A partir de este punto, es válido plantear un equilibrio entre lo teórico y práctico, ya que las asignaturas vinculadas a la ética y legislación periodística tienen un componente principalmente teórico. Sin embargo, en las asignaturas prácticas, los alumnos ponen a prueba y evidencian la formación valórica asociada a la profesión.

El denominado “método por saturación”, planteado por Christians y Covert, plantea que los aspectos éticos deberían estar contenidos en gran parte de los cursos de la carrera y así los estudiantes asimilarían las cuestiones éticas en el ejercicio práctico, como por ejemplo en el reporteo (ápud Díaz del Campo, 2013). La principal defensa a este método alude a que la ética es inherente al periodismo, que una correcta formación debería considerar desde los primeros años de carrera estos contenidos y que tendría el beneficio de no generar una discusión de estas materias de manera aislada solo en unas asignaturas y no comprenderlo como algo global. Cabe precisar que el "método de saturación" aparece en programas de periodismo, principalmente en Europa y en los Estados Unidos, los cuales no cuentan con asignaturas específicas de ética.

Si bien este último punto plantea una posición distinta a la que existe a nivel local, sí es destacable la conjugación de lo teórico y lo práctico que plantea. Muchas veces en el ensayo y error, un estudiante (al realizar trabajos prácticos asociados a una asignatura) se encuentra con un dilema ético real, al que debe responder en función de su formación valórica. En este sentido, es válido plantear un justo equilibrio entre los aspectos teóricos del plan de estudio y la puesta en práctica en los ejercicios en terreno, donde los riesgos a la ética y la legislación pueden ser identificados en un contexto académico. 
Un punto importante para reflexionar, en función de los resultados de este estudio, tiene relación con que lo declarado por los estudiantes no se condice con sus primeras experiencias personales. La práctica "publicar historias sin verificar el contenido" es la que obtuvo el segundo mayor rechazo por parte de los estudiantes mientras cursan la carrera, pero es la que más identifican los editores cuando los reciben para realizar su práctica profesional. En este punto es fundamental insistir en verificar el origen de la fuente, examinar el dato una y otra vez. En la actualidad, la tecnología les permite a los profesores verificar la autenticidad y fiabilidad de lo que reportean los alumnos, más allá del olfato que entrega el ejercicio profesional.

Por lo tanto, en este punto es fundamental recordar el ya señalado “ensayo y error", más aún cuando los estudiantes (al ser nativos digitales) utilizan la Internet como la principal fuente de información, que bien utilizada es fiable, pero pueden privilegiarla en desmedro del contacto presencial (a veces un llamado), lo que les resta el ejercicio en terreno. Entregar información verificable, de manera irrenunciable, es algo que el alumno debería tener muy interiorizado en su quehacer.

El periodista en el ejercicio de su profesión, como señala Urzúa (2005: 17), enfrenta una situación compleja porque "la forma de hacer pública su profesión consiste en precisamente en publicar, en colocar el objeto de su trabajo, el mensaje informativo, en conocimiento de la sociedad". Ahora bien, esa tarea implica que (desde la formación académica y para cumplir un rol social) se debe comprender que detrás de esos hechos hay personas. Así, es importante sensibilizar acerca del tratamiento que reciben las personas en los medios cuando se difunden acontecimientos en que se ven envueltas, principalmente asociado a tragedias, enfermedades, catástrofes, entre otros. En este punto, es clave insistir en el respeto por la dignidad de las personas.

En el actual contexto en que se destapan escándalos de diversa índole, cobertura de noticias falsas, casos de plagios de entrevistas o investigaciones publicadas en medios de otros países (que reflejan conductas contrarias no solo a la ley, sino también a la moral y a la ética), Rushworth Kidder advierte que sería imposible "sobrevivir en el siglo XXI con la ética del siglo XX", advierte que "esto significa que no sólo estamos hablando de la ética profesional de los periodistas, sino de la respuesta a los desafíos morales de personas e instituciones que integran la sociedad contemporánea” (Santibañez, 2013: 77).

Un desafío que va más allá de una disciplina en particular y que desde la academia resulta no solo indispensable, sino también apremiante el tener que recogerlo, por el rol que ocupa en la sociedad.

\section{Fuentes consultadas}

Canal 13 UC (2012). "Libro de orientaciones programáticas de Canal 13". Extraída el 3/X/2017 desde http://www.anatel.cl/wp-content/uploads/2017/07/orientacionesprogramaticas-canal-13.pdf

Chilevisión (2006). "Guías editoriales". Extraída el 3/X/2017 desde http://www. chvnoticias.cl/site/artic/20131218/asocfile/20131218173822/guias_editoriales.pdf 
Colegio de Periodistas de Chile (2015). "Código de ética". Extraída el 3/X/2017 desde http://www.colegiodeperiodistas.cl/p/etica-periodistica.html

Díaz del Campo Lozano, J. (2013). "El lugar de la Ética en la formación del periodista. Un estudio de la situación en la Unión Europea”. Cuadernos.Info, núm. 33, pp. 113-120. Extraída el 3/X/2017 desde https://doi.org/10.7764/cdi.33.529

Mega (2015). “Orientaciones programáticas 2015”. Extraída el 3/X/2017 desde http:// static-mega.mdstrm.com/_common/docs/orientaciones_4-feb-2015.pdf

Mellado, C. y otros (2015). "Estudiantes de periodismo en Chile: Percepción sobre la profesión, su futuro laboral y el desempeño de los medios". Extraída el 3/X/2017 desde http://www.periodismoucv.cl/wp-content/uploads/2015/08/Informe-FINAL_Estudiantesde-Periodismo-en-Chile.pdf

Ministerio Secretaría General del Gobierno de Chile (2013). "Ley 20709 sobre las libertades de opinión e información y ejercicio del periodismo". Extraída el 3/X/2017 desde https://www.leychile.cl/Navegar?idNorma=186049

Pulitzer, J. (1904). “The College of Journalism”. North American Review. Vol. 178, núm. 570, pp.641-680. Extraída el 3/X/2017 desde http://www.unz.org/Pub/NorthAmericanRev1904may-00641

\section{Santibañez, A.}

_(2013). ¿Ética Periodística? ja, ja, ja. Santiago de Chile: Bravo y Allende Editores.

_(1994). Introducción al periodismo. Santiago de Chile: Editorial Los Andes.

TVN, Televisión Nacional de Chile (2009). "Orientaciones programáticas y editoriales". Extraída el 3/X/2017 desde http://estaticos.tvn.cl/skins/especiales/ tvncorporativo/201410281740/documentos/OP2014.pdf

Urzúa Aracena, M. (2005). Periodismo y ética. Temas actuales. Santiago de Chile: Centro de Estudios Bicentenario. 